\title{
STUDENT ACHIEVEMENT IN A PHARMACOTHERAPY PRACTICE COURSE: A CASE STUDY AT AN INDONESIAN PHARMACY SCHOOL
}

\author{
Lailaturrahmi $^{1 *}$, Elsa Badriyya ${ }^{1}$ \\ ${ }^{1}$ Bagian Farmakologi dan Farmasi Klinik, Fakultas Farmasi, Universitas Andalas, Padang - INDONESIA \\ Submitted: 04 March 2020; Final Revision from Author: 22 August 2020; Accepted: 06 October 2020
}

\begin{abstract}
Background: Indonesian pharmacy schools are expected to meet required clinical pharmacy components and the proportion of practical courses according to nationally established standards. This is essential to produce competent Indonesian pharmacists. The implementation of Pharmacotherapy of Gastrointestinal, Respiratory Tract Diseases, and Special Conditions Practice was one of the measures taken to meet this requirement. This case study aims to explore obstacles in Pharmacotherapy of Gastrointestinal, Respiratory Tract Diseases, and Special Conditions Practice.

Case discussion: Pharmacotherapy of Gastrointestinal, Respiratory Tract Diseases, and Special Conditions (FAF 314) Practice was conducted using group case study with SOAP (subjective, objective, assessment, plan) worksheet. During the sixth week of practice, a modified OSCE was conducted to assess the learning process. The skills that were assessed included problem identification, problem-solving, drug information service, effective communication, as well as attitude and professionalism. However, the students' average score in this assessment was about 1-2 of maximum score 3, and the required passing score was 2 .

Conclusion: The sub-optimal students' achievement in the mid-term assessment of Pharmacotherapy of Gastrointestinal, Respiratory Tract Diseases, and Special Conditions Practice may be due to the students' obstacles in understanding the information from literature and showing effective communication skills and professional attitude in drug information provision. To address these issues, further measures such as constructive alignment analysis of this practice, revising practice activities design and allocating adequate time to practice effective communication skills and professional attitude in drug information provision.
\end{abstract}

Keywords: constructive alignment, communication, pharmacotherapy practice, OSCE, SOAP

\section{ABSTRAK}

Latar belakang: Perguruan tinggi Farmasi Indonesia dituntut untuk memenuhi proporsi muatan farmasi klinik dalam kurikulum serta bobot pelaksanaan praktikum yang sesuai dengan standar nasional yang ditetapkan. Hal tersebut dilakukan untuk menghasilkan apoteker Indonesia yang berkompeten. Pelaksanaan praktikum Farmakoterapi Penyakit Saluran Cerna, Saluran Napas, dan Kondisi Khusus merupakan upaya untuk memenuhi tuntutan ini. Studi kasus ini bertujuan menganalisis kendala yang dihadapi dalam pelaksanaan praktikum Farmakoterapi Penyakit Saluran Cerna, Saluran Napas, dan Kondisi Khusus.

Diskusi kasus: Praktikum Farmakoterapi Penyakit Saluran Cerna, Saluran Napas, dan Kondisi Khusus dilaksanakan dengan model diskusi kasus berkelompok dengan lembar kerja SOAP (subjective, objective, assessment, plan). Asesmen pembelajaran menggunakan OSCE yang dimodifikasi dilaksanakan pada minggu

$\overline{\text { *corresponding author, contact: lailaturrahmi@phar.unand.ac.id }}$ 
keenam praktikum. Keterampilan yang diujikan mencakup penetapan masalah, penyelesaian masalah, pelayanan informasi obat, komunikasi efektif, serta sikap dan profesionalitas. Kendati demikian, rerata skor per keterampilan yang diperoleh mahasiswa dalam asesmen mid semester ini berkisar antara 1-2 dari skor maksimal 3, dengan skor batas lulus 2 .

Kesimpulan: Pencapaian mahasiswa dalam asesmen mid semester Praktikum Farmakoterapi Penyakit Saluran Cerna, Saluran Nafas, dan Kondisi Khusus kurang optimal. Hal tersebut disebabkan karena adanya kendala dalam memahami informasi dari literatur, menunjukkan keterampilan komunikasi efektif, serta sikap profesional dalam pemberian informasi obat. Untuk itu, diperlukan tindak lanjut berupa analisis constructive alignment praktikum, perbaikan desain aktivitas praktikum, dan alokasi waktu yang memadai untuk melatih keterampilan komunikasi dan sikap profesional dalam pemberian informasi obat.

Kata kunci: constructive alignment, komunikasi, praktikum farmakoterapi, OSCE, SOAP

\section{PRACTICE POINTS}

- Merupakan artikel pertama yang membahas pelaksanaan praktikum farmakoterapi di perguruan tinggi farmasi Indonesia

- Artikel ini mengkaji kendala yang dihadapi dalam pelaksanaan praktikum farmakoterapi dalam berbagai aspek, antara lain aspek desain praktikum, aspek karakteristik mahasiswa, aspek pembelajaran, dan implikasinya dalam menunjang pencapaian kompetensi sebagai apoteker.

- Terdapat rekomendasi yang dapat diterapkan untuk perbaikan pembelajaran berbasis tim dalam konteks farmasi klinis, khususnya dalam praktikum farmakoterapi.

\section{PENDAHULUAN}

Profesi apoteker merupakan profesi yang bertanggung jawab memastikan keamanan pengobatan pasien. Untuk menghasilkan apoteker yang kompeten dalam tugasnya, para pendidik dan akademisi memegang peranan dan tanggung jawab yang besar. ${ }^{1}$ Dalam ruang lingkup yang lebih besar, pendidikan farmasi bertujuan untuk menyediakan kompetensi yang dibutuhkan mahasiswa farmasi agar dapat berperan dalam sistem pelayanan kesehatan multidisiplin. ${ }^{2}$ Berbagai institusi pendidikan pun membangun pendidikan farmasi untuk memenuhi tuntutan profesi farmasi, antara lain dalam berpikir kritis, menyelesaikan permasalahan terkait terapi, dan membuat keputusan dalam farmakoterapi. ${ }^{3,4}$

Sejumlah upaya dilakukan terkait peningkatan standar pendidikan farmasi untuk menghasilkan apoteker Indonesia yang kompeten. Dalam hal kurikulum, Asosiasi Pendidikan Tinggi Farmasi
Indonesia (APTFI) mensyaratkan proporsi muatan farmasi klinik/sosial/dan administrasi sebesar 15$20 \%$ untuk mendukung pencapaian kompetensi lulusan. Selain itu, muatan ilmu juga harus seimbang dengan praktik dengan memanfaatkan pendekatan pembelajaran berpusat pada mahasiswa (studentcentered learning). Lebih lanjut lagi, standar akreditasi sarjana farmasi yang ditetapkan oleh Lembaga Akreditasi Mandiri Perguruan Tinggi Kesehatan (LAM-PTKes) mendorong pelaksanaan praktikum dengan proporsi minimal 20\% dari total keseluruhan sks dalam pendidikan sarjana.

Oleh karena itu, Program Studi Sarjana Farmasi (PSSF) Fakultas Farmasi Universitas Andalas melakukan beberapa perubahan dalam pembelajaran, salah satunya dengan menambah jumlah sks praktikum untuk menunjang tercapainya keterampilan mahasiswa. Terkait dengan itu, Praktikum Farmakoterapi Penyakit Saluran Cerna, 
Saluran Napas, dan Kondisi Khusus merupakan salah satu praktikum yang baru pertama kali dilaksanakan pada semester ganjil tahun akademik 2019/2020, sejalan dengan implementasi kurikulum baru (Kurikulum 2017). Studi kasus ini bertujuan untuk menganalisis kendala yang dihadapi dalam pelaksanaan praktikum tersebut beserta alternatif solusi untuk perbaikan mutu ke depannya.

\section{DESKRIPSI KASUS}

Studi dilakukan dengan metode kualitatif terhadap pelaksanaan Praktikum Farmakoterapi Penyakit Saluran Cerna, Saluran Napas, dan Kondisi Khusus yang meliputi persiapan, pelaksanaan praktikum, pelaksanaan asesmen, dan hasil asesmen. Data yang digunakan dalam studi kasus ini adalah nilai asesmen mid semester serta dokumen pembahasan hasil asesmen mid semester. Populasi dari studi adalah 135 orang mahasiswa angkatan 2017 Fakultas Farmasi Universitas Andalas.

Asesmen mid semester dilakukan setelah menyelesaikan lima modul praktikum. Asesmen dilaksanakan dengan format OSCE yang dimodifikasi, di mana penguji langsung berperan sebagai pemeran standar (PS). Pada OSCE ini, terdapat empat station yang melibatkan interaksi dengan pemeran standar, sedangkan satu station hanya menggunakan lembar kerja. Di setiap station, disediakan literatur untuk mencari informasi mengenai algoritma terapi, klasifikasi obat, efek samping obat, serta informasi lainnya terkait obat. Terdapat lima modul yang diujikan dalam OSCE yaitu Tukak Peptik, Manajemen Nyeri, Diare, ISPA, dan Sirosis Hati. Sementara itu, keterampilan yang diujikan mencakup penetapan masalah, penyelesaian masalah, pelayanan informasi obat, komunikasi efektif, serta sikap dan profesionalitas. Komponen keterampilan yang diujikan berbeda di setiap topik, bergantung pada materi yang telah diajarkan. Untuk menilai mahasiswa, digunakan rubrik penilaian dengan rating scale $0-3$. Waktu pelaksanaan ujian adalah lima menit untuk setiap station.
Tabel 1. Rerata skor asesmen mid semester Praktikum Farmakoterapi Penyakit Saluran Cerna, Saluran Napas, dan Kondisi Khusus berdasarkan modul yang diujikan $(n=135)$

\section{Modul yang Diujikan Rerata+SD}

\begin{tabular}{ll} 
Tukak Lambung & $1,61 \pm 0,83$ \\
Manajemen Nyeri & $1,64 \pm 1,18$ \\
Diare & $1,44 \pm 0,66$ \\
ISPA & $0,57 \pm 0,83$ \\
Sirosis Hati & $1,95 \pm 1,01$ \\
\hline
\end{tabular}

Skor diukur dengan rating scale 0-3

Hasil asesmen dianalisis dan dirata-ratakan. Berdasarkan Tabel 1 diatas, diketahui bahwa rerata skor mahasiswa berdasarkan modul yang diujikan kurang dari batas lulus (2). Sementara itu, rerata skor mahasiswa berdasarkan keterampilan yang diujikan (lintas modul) lebih tinggi dibandingkan rerata skor setiap modul, seperti terlihat pada tabel di bawah ini.

Tabel 2. Rerata skor asesmen mid semester Praktikum Farmakoterapi Penyakit Saluran Cerna, Saluran Napas, dan Kondisi Khusus berdasarkan keterampilan yang diujikan $(\mathrm{n}=135)$

$\begin{array}{lc}\text { Keterampilan yang Diujikan } & \text { Rerata+SD } \\ \text { Pelayanan Informasi Obat } & 1,63 \pm 0,84 \\ \text { Penetapan Masalah } & 2,36 \pm 1,11 \\ \text { Penyelesaian Masalah } & 1,81 \pm 0,83 \\ \text { Komunikasi Efektif } & 1,21 \pm 0,83 \\ \text { Sikap dan Profesionalitas } & 1,59 \pm 0,70\end{array}$

Skor diukur dengan rating scale 0-3

Hasil asesmen ini selanjutnya didiskusikan oleh tim dosen penguji untuk mengetahui kendala yang dihadapi mahasiswa saat menjawab soal asesmen mid semester, sekaligus untuk mengevaluasi pelaksanaan lima modul praktikum yang diujikan. Dari diskusi tersebut, diperoleh sejumlah catatan terkait kendala yang dihadapi mahasiswa selama asesmen mid semester tersebut, seperti yang terlihat pada Tabel 3 di bawah ini. Catatan tersebut didasarkan pada hasil pengamatan dosen penguji terhadap performa mahasiswa selama OSCE dan dikombinasikan dengan nilai yang diperoleh mahasiswa. Data persentase mahasiswa yang memiliki skor kecil dari dua ditampilkan dalam Tabel 3. 
Tabel 3. Kendala yang dihadapi mahasiswa menurut pengamatan dosen penguji pada saat asesmen Praktikum Farmakoterapi Penyakit Saluran Cerna, Saluran Napas, dan Kondisi Khusus berdasarkan keterampilan yang diujikan

\begin{tabular}{|c|c|c|}
\hline $\begin{array}{l}\text { Modul yang } \\
\text { Diujikan }\end{array}$ & Keterampilan & Kendala \\
\hline Tukak Lambung & $\begin{array}{l}\text { Penetapan dan penyelesaian } \\
\text { masalah }\end{array}$ & $\begin{array}{l}\text { - 50\% mahasiswa tidak mampu menetapkan masalah karena } \\
\text { terbatasnya pengetahuan tentang penggolongan/klasifikasi } \\
\text { obat, misalnya metronidazole diklasifikasikan sebagai } \\
\text { golongan PPI. } \\
\text { - } 35 \% \text { mahasiswa kurang mampu memberikan pelayanan } \\
\text { informasi obat seperti signa antibiotik seharusnya setiap } \\
12 \text { jam, namun mahasiswa menginformasikannya dua kali } \\
\text { sehari serta aturan pakai sukralfat masih sering salah. }\end{array}$ \\
\hline Manajemen Nyeri & Penyelesaian masalah & $\begin{array}{l}\text { 32\% mahasiswa tidak mampu memanfaatkan algoritma dan } \\
\text { memilih dosis obat dari literatur yang disediakan. }\end{array}$ \\
\hline Diare & $\begin{array}{l}\text { - Penyelesaian masalah } \\
\text { - Komunikasi efektif } \\
\text { - Sikap dan perilaku } \\
\text { profesional }\end{array}$ & $\begin{array}{l}\text { - } 44 \% \text { mahasiswa tidak mampu membedakan diare spesifik } \\
\text { dan non spesifik. } \\
\text { - } 70 \% \text { mahasiswa tidak mampu menyampaikan informasi } \\
\text { obat termasuk tujuan terapi, dosis dan aturan pakai. } \\
\text { - } 48 \% \text { mahasiswa kurang mengetahui sikap profesional } \\
\text { termasuk perkenalan, menatap pasien dan kelancaran } \\
\text { berbicara. }\end{array}$ \\
\hline ISPA & Penyelesaian masalah & $\begin{array}{l}\text { - } 83 \% \text { mahasiswa tidak mampu menafsirkan algoritma dan/ } \\
\text { atau tabel dosis } \\
\text { - } 93 \% \text { Mahasiswa tidak memahami klasifikasi/ } \\
\text { penggolongan obat, misalnya obat yang termasuk golongan } \\
\text { fluoroquinolone }\end{array}$ \\
\hline Sirosis Hati & Penyelesaian masalah & $\begin{array}{l}\text { - } 26 \% \text { mahasiswa tidak mampu menentukan Child-Pugh Score } \\
\text { pasien. } \\
\text { - } 54 \% \text { mahasiswa paham makna Child-Pugh score, namun tidak } \\
\text { mampu memanfaatkan literatur dengan baik (contoh: ketika } \\
\text { Child-Pugh score } 8 \text {, bukan berarti harus dilakukan penurunan } \\
\text { dosis obat 25\%, sebaiknya cek literatur dulu) }\end{array}$ \\
\hline
\end{tabular}

\section{PEMBAHASAN}

Praktikum Farmakoterapi Penyakit Saluran Cerna, Saluran Nafas, dan Kondisi Khusus merupakan pembelajaran pada tahap lanjutan (semester kelima) dalam pendidikan Sarjana Farmasi. Untuk mengikuti praktikum ini, mahasiswa diharapkan telah menyelesaikan matakuliah dasar dan prasyarat, seperti Anatomi Fisiologi Manusia, Patofisiologi, dan Farmakologi. Pemahaman konsep anatomi dan fisiologi manusia, patofisiologi, dan farmakologi dibutuhkan untuk memahami farmakoterapi, suatu ilmu yang mempelajari penerapan farmakologi untuk terapi penyakit atau kondisi khusus.
Kegiatan praktikum dimulai dengan rapat persiapan praktikum termasuk menyiapkan diktat, pelaksanaan praktikum menggunakan model diskusi berkelompok dan lembar SOAP, pelaksanaan asesmen dan hasil asesmen. Dari rapat persiapan praktikum, disepakati bahwa penilaian praktikum ini terdiri dari penilaian harian, asesmen mid semester, dan asesmen akhir semester. Penilaian harian terdiri dari empat komponen, yakni pretest, kemampuan mahasiswa dalam identifikasi kasus, kemampuan komunikasi dan konseling, dan aktivitas dalam kelompok berupa lembar kerja SOAP dan presentasi. 
Umpan balik terhadap pre-test individu dan tugas kelompok juga diberikan pada hari yang sama agar hasilnya dapat langsung diketahui mahasiswa. Dalam kelompok, dosen sebagai fasilitator memberikan kesempatan kepada mahasiswa untuk bertanya dan menyampaikan pendapat atau informasi yang diketahuinya, serta dapat pula ditanggapi dan dilengkapi oleh rekan sekelompoknya. Meski demikian, tidak semua mahasiswa mau aktif berpendapat, sehingga dosen perlu memberikan stimulus atau meminta mahasiswa yang kurang aktif untuk memberikan tanggapannya terkait kasus yang diberikan dalam praktikum.

Pembagian kelompok mahasiswa pada Praktikum Farmakoterapi Penyakit Saluran Cerna, Saluran Nafas, dan Kondisi Khusus dilakukan berdasarkan kesepakatan mahasiswa dalam satu shift praktikum, tidak berdasarkan karakteristik tertentu maupun menggunakan randomisasi. Umumnya di setiap kelompok mahasiswa, terdapat beberapa mahasiswa yang lebih menonjol dan aktif. Meski ada perbedaan pendapat mengenai metode pengelompokan mahasiswa dan kaitannya dalam performa pembelajaran, belum ditemukan satu metode pengelompokan yang ideal. Menurut penelitian yang dilakukan di Amerika Serikat, pengelompokkan para mahasiswa berdasarkan level IPK menantang para mahasiswa berperforma tinggi untuk meningkatkan kemampuan mereka, sekaligus menciptakan kelompok dengan performa rendah. Sebaliknya, dengan menggabungkan mahasiswa dengan IPK beragam dalam satu kelompok memungkinkan mahasiswa yang memiliki kemampuan kurang baik untuk belajar dari teman-temannya. ${ }^{5}$ Perlu juga diperhatikan bahwa kepribadian mahasiswa dapat mempengaruhi pembelajaran. ${ }^{6}$ Mahasiswa yang aktif berpartisipasi tidak selalu memiliki pengetahuan yang lebih baik, tetapi mereka memiliki kepribadian ekstrovert, sehingga cenderung mendominasi pembelajaran dalam kelompok. ${ }^{7}$ Sementara itu, introvert umumnya kurang menyukai pembelajaran dalam kelompok dibandingkan ekstrovert. ${ }^{8}$ Oleh karena itu, diperlukan strategi yang tepat dalam menyusun kelompok mahasiswa untuk mencapai manfaat pembelajaran yang optimal. ${ }^{5}$

Mahasiswa yang mengikuti praktikum farmakoterapi ini merupakan generasi $Z$ yang memiliki karakteristik berbeda dengan generasi-generasi sebelumnya. Beberapa karakteristik pembelajaran generasi Z antara lain menyukai konektivitas dengan dunia tanpa batas, mengonsumsi berbagai informasi, menyukai pembelajaran daring yang memungkinkan fleksibilitas, serta mudah terdistraksi. Disamping itu, pembelajaran yang melibatkan generasi $\mathrm{Z}$ mengharuskan dosen berkomunikasi dengan cara baru yang menarik minat mahasiswa, sekaligus memungkinkan penyampaian komunikasi kepada mahasiswa dengan cara yang mudah dipahami. ${ }^{9}$ Proses pembelajaran dalam praktikum farmakoterapi ini mendukung generasi $\mathrm{Z}$ dengan memberikan kesempatan bagi mereka untuk mengakses literatur terkini melalui berbagai sumber luring maupun daring. Dosen maupun asisten praktikum juga memberikan umpan balik secara responsif, sesuatu yang juga disenangi oleh mahasiswa generasi Z. Hanya saja, diperlukan usaha baik dari sisi dosen maupun mahasiswa untuk memanfaatkan karakteristik ini menjadi pembelajaran yang optimal. Akses mahasiswa terhadap berbagai sumber informasi secara tanpa batas perlu diiringi dengan pemilahan sumber informasi yang dapat dipercaya. Selain itu, mahasiswa pun harus dilatih untuk berkonsentrasi untuk meningkatkan kapasitas memori. ${ }^{10}$ Dengan demikian, informasi baru yang diperoleh mahasiswa selama praktikum dapat dipertahankan dalam jangka panjang.

Hasil asesmen mid semester menunjukkan bahwa rerata skor mahasiswa masih rendah. Dari hasil catatan diskusi dosen (Tabel 3), terdapat beberapa kendala yang dialami mahasiswa selama asesmen. Mahasiswa mengalami kendala dalam memahami algoritma terapi, dosis, dan aturan pakai obat dari literatur yang disediakan di setiap station. Aturan pakai antibiotik yang lebih spesifik, seperti 'setiap 12 jam', bukannya 'dua kali sehari' pun masih disalahartikan oleh mahasiswa. Tabel 3 juga menunjukkan mahasiswa juga mengalami kendala dalam memahami klasifikasi obat. Hal ini disayangkan karena dalam kurikulum 2017 di Program Studi Sarjana Farmasi Universitas Andalas, klasifikasi obat-obatan telah diajarkan pada mata kuliah Farmakologi, yang dibagi dalam tiga mata kuliah yakni Farmakologi Dasar, Farmakologi Sistem Saraf dan Kardiovaskular, serta Farmakologi Anti Infeksi dan Endokrin. 
Selain itu, dari Tabel 3 juga diketahui bahwa mahasiswa mengalami kendala terkait aspek keterampilan komunikasi efektif serta sikap dan profesionalitas. Mahasiswa diharapkan untuk menyampaikan informasi obat secara lengkap, mencakup tujuan terapi, dosis dan aturan pakai. Mahasiswa juga diharapkan mampu menunjukkan sikap profesional dengan memperkenalkan diri, menatap pasien, serta berbicara dengan lancar. Dalam praktikum, mahasiswa memiliki kesempatan untuk melatih keterampilan komunikasi melalui diskusi kelompok dan presentasi. Akan tetapi, keterbatasan waktu menyebabkan mahasiswa tidak memiliki kesempatan yang memadai untuk berlatih konseling atau pelayanan informasi obat selama praktikum. Kalaupun ada, hanya perwakilan mahasiswa dalam satu shift praktikum yang memiliki kesempatan untuk tampil dan memeragakan sesi konseling atau pelayanan informasi obat sesuai modul yang dipraktikumkan.

Dalam asesmen mid semester, terdapat beberapa keterampilan yang diuji meliputi penetapan masalah, penyelesaian masalah, pelayanan informasi obat, komunikasi efektif, serta sikap dan profesionalitas. Mahasiswa tidak hanya diuji kemampuan penyampaian informasi obat kepada pasien, tetapi juga kemampuan untuk membuat rekomendasi tertulis kepada dokter dalam setting ujian OSCE yang dimodifikasi. Baik keterampilan penetapan masalah $^{11}$ maupun penyelesaian masalah ${ }^{12}$ termasuk dalam aspek penalaran klinis (clinical reasoning) yang pada akhirnya mendukung apoteker dalam membuat keputusan klinis (clinical decision-making). ${ }^{13}$ Pelayanan informasi obat, di sisi lain, juga merupakan keterampilan yang esensial bagi apoteker ${ }^{14}$ untuk meningkatkan keamanan penggunaan obat dan mencapai tujuan terapi yang optimal. ${ }^{15}$ Pelayanan informasi obat ini dapat dilakukan secara lisan kepada pasien dalam bentuk konseling dan edukasi, ${ }^{16}$ maupun dalam bentuk rekomendasi tertulis kepada dokter untuk perubahan terapi. ${ }^{17} \mathrm{Hal}$ ini menunjukkan bahwa asesmen mid semester yang dilakukan dalam Praktikum Farmakoterapi Penyakit Saluran Cerna, Saluran Nafas, dan Kondisi Khusus ini relevan terhadap kompetensi apoteker yang dibutuhkan.
Meski demikian, asesmen mid semester ini tidak sepenuhnya sejalan dengan tugas dan keterampilan yang ditekankan selama proses praktikum. Soalsoal yang diberikan sedikit sekali menyentuh keterampilan mahasiswa dalam menuliskan dokumen SOAP, dan justru lebih banyak menguji kemampuan mahasiswa dalam mengidentifikasi masalah dan memecahkannya (aspek assessment dan plan). Aktivitas praktikum yang dilaksanakan secara berkelompok dapat menyebabkan tidak semua mahasiswa mampu melakukan pencarian informasi di literatur secara individu. Keterampilan penyampaian informasi obat juga tidak ditekankan dalam praktikum ini karena keterbatasan waktu. Hal ini mengindikasikan desain praktikum Farmakoterapi Penyakit Saluran Cerna, Saluran Nafas, dan Kondisi Khusus ini belum sepenuhnya memenuhi kaidah constructive alignment, yang menekankan hubungan antara capaian pembelajaran, metode pembelajaran, dan penilaian pembelajaran. Menurut constructive alignment, baik metode pembelajaran maupun penilaian pembelajaran harus mampu mendukung tercapainya capaian pembelajaran. ${ }^{18}$ Masalah kurangnya constructive alignment, khususnya pada mata kuliah Farmakoterapi juga terjadi di institusi pendidikan lain, antara lain ketidaksesuaian antara desain instruksional dengan tujuan program, ketidaksesuaian capaian pembelajaran mata kuliah dengan sub-capaian pembelajaran, dan ketidaksesuaian level kognitif pada capaian pembelajaran. ${ }^{19}$ Analisis constructive alignment terhadap mata kuliah dan topik-topik yang diajarkan perlu dilakukan agar masalah ini dapat teratasi, sehingga proses pembelajaran dapat ditingkatkan.

Selain itu, juga diperlukan perbaikan desain aktivitas praktikum agar mahasiswa dapat mencapai tujuan pembelajaran yang diharapkan. Kendala mahasiswa dalam memahami literatur ditindaklanjuti oleh tim dosen pengampu praktikum ini dengan memberikan materi dan pendampingan bagi mahasiswa dalam memahami literatur yang digunakan dalam Praktikum Farmakoterapi Penyakit Saluran Cerna, Saluran Nafas, dan Kondisi Khusus ini. Materi dan pendampingan dalam setiap kelompok praktikum diberikan mulai modul enam yang dilaksanakan setelah asesmen mid semester. Selain itu, kendala 
mahasiswa dalam mempraktikkan komunikasi efektif dan sikap profesional kepada pasien dapat ditindaklanjuti dengan mengalokasikan waktu yang memadai untuk melatih keterampilan ini. Keterbatasan waktu dapat disiasati dengan menugaskan mahasiswa untuk berlatih secara mandiri dan mengirimkan dokumentasi latihan berupa rekaman untuk dievaluasi oleh dosen. Namun, hal ini tidak kami lakukan pada praktikum ini karena keterbatasan waktu dan kekhawatiran untuk membebani mahasiswa karena berdasarkan kurikulum Program Studi Sarjana Farmasi di institusi kami, terdapat empat praktikum yang harus diikuti oleh mahasiswa semester lima, dimana Praktikum Farmakoterapi Penyakit Saluran Cerna, Saluran Nafas, dan Kondisi Khusus merupakan salah satunya.

Terkait kendala mahasiswa dalam menerapkan konsep-konsep Farmakologi yang telah mereka pelajari pada asesmen mid semester, diperlukan untuk memeriksa koherensi antar mata kuliah agar mahasiswa memperoleh pemahaman yang ajeg. Selain itu, juga diperlukan beberapa strategi untuk memperbaiki retensi memori mahasiswa, terutama terkait mata kuliah yang menjadi dasar untuk memahami Farmakoterapi, seperti Anatomi dan Fisiologi Manusia, Patofisiologi, dan Farmakologi. Terdapat bukti yang menunjukkan bahwa tugas bacaan dan persiapan sebelum kegiatan pembelajaran terbukti dapat meningkatkan retensi pengetahuan dan performa mahasiswa dalam ujian $^{20-22}$. Hal ini menandakan bahwa mahasiswa yang mempersiapkan diri sebelum aktivitas perkuliahan, yang ditandai dengan skor pre-test yang lebih tinggi, mampu menguatkan konsep dasar dari bacaan, sehingga dapat lebih fokus pada informasi yang lebih terperinci. ${ }^{21}$ Strategi berupa pemberian tugas pendahuluan sebelum praktikum dan pre-test telah kami laksanakan pada praktikum ini, meski tampaknya tidak terlalu berpengaruh terhadap skor asesmen mid semester. Hal ini menjadi catatan evaluasi bagi tim dosen untuk memperbaiki desain tugas pendahuluan dan pre-test agar lebih efektif dalam meningkatkan retensi memori mahasiswa.

Dalam studi kasus ini, kami tidak meminta umpan balik dari mahasiswa, baik melalui survei maupun dengan metode lain seperti focus group discussion
(FGD). Hal ini menjadi keterbatasan dalam studi yang kami lakukan, mengingat umpan balik mahasiswa juga merupakan sumber data yang berharga dalam melakukan evaluasi kegiatan pembelajaran.

\section{KESIMPULAN}

Mahasiswa mengalami kendala dalam memahami informasi dari literatur, menunjukkan keterampilan komunikasi efektif, dan sikap profesional pada asesmen mid semester Praktikum Farmakoterapi Penyakit Saluran Cerna, Saluran Nafas, dan Kondisi Khusus. Kendala ini terjadi akibat konten soal OSCE yang tidak sepenuhnya sejalan dengan tugas dan keterampilan yang diberikan selama praktikum serta keterbatasan waktu untuk melatih keterampilan komunikasi dan penyampaian informasi obat.

\section{SARAN}

Dosen perlu memastikan kesesuaian antara praktikum yang akan diberikan dengan mata kuliah sebelumnya yang terkait untuk memastikan mahasiswa telah memiliki pemahaman dasar yang dibutuhkan. Analisis constructive alignment terhadap praktikum dan modul yang diberikan juga perlu dilakukan agar tujuan pembelajaran sejalan dengan metode penilaian dan proses pembelajaran.

Untuk meningkatkan retensi memori mahasiswa terhadap konsep Anatomi dan Fisiologi, Patofisiologi, dan Farmakologi yang terkait dengan praktikum, dosen perlu mendesain tugas pendahuluan dan pretest untuk meningkatkan retensi memori mahasiswa. Mengingat mahasiswa juga harus mencapai penguasaan keterampilan secara individu, dosen perlu mendesain cara untuk melatih keterampilan komunikasi dan sikap profesional mahasiswa secara individual agar semua mahasiswa memiliki keterampilan yang diharapkan, bukan hanya sebagian kecil mahasiswa saja. Selain itu, pembagian kelompok mahasiswa dapat dirancang sedemikian rupa sehingga tidak ada peserta atau kelompok yang terlalu mendominasi, sementara kelompok atau mahasiswa lainnya tidak berpartisipasi aktif.

Diperlukan pendekatan khusus bagi mahasiswa generasi $\mathrm{Z}$ yang mudah terdistraksi dan memiliki akses informasi yang tidak terbatas. Memberikan 
relevansi konteks pembelajaran dan umpan balik segera kepada mahasiswa merupakan langkah yang dapat dilakukan.

\section{DAFTAR SINGKATAN}

\begin{tabular}{|c|c|c|}
\hline APTFI & $\begin{array}{l}\text { Asosiasi Perguruan Tinggi } \\
\text { Indonesia }\end{array}$ & Farmasi \\
\hline ISPA & $\begin{array}{l}\text { Infeksi Saluran Pernapasan } \\
\text { Atas }\end{array}$ & bagian \\
\hline \multirow[t]{2}{*}{ LAM-PTKes: } & : Lembaga & Mandiri \\
\hline & Perguruan Tinggi Kesehatan & \\
\hline OSCE & $\begin{array}{l}\text { Objective Structured } \\
\text { Examination }\end{array}$ & Clinical \\
\hline PPI & : Proton Pump Inhibitor & \\
\hline PSSF & : Program Studi Sarjana & \\
\hline SOAP & : Subjective, Objective, Assessment & at, Plan \\
\hline
\end{tabular}

\section{DEKLARASI KEPENTINGAN}

Para penulis mendeklarasikan bahwa tidak terdapat konflik kepentingan apapun terkait studi pada naskah ini.

\section{KONTRIBUSI PENULIS}

Lailaturrahmi - mengembangkan rancangan studi kasus, mengumpulkan data, analisis data, dan menulis manuskrip.

Elsa Badriyya - mengumpulkan data, analisis data, dan menulis manuskrip.

\section{UCAPAN TERIMA KASIH}

Penulis mengucapkan terima kasih kepada Prof. Dr. Apt., Armenia, MS. sebagai Kepala Laboratorium Farmakoterapi, serta Apt. Dita Permatasari, M.Farm., Apt. Fitri Rachmaini, S.Farm., M.Si., dan Apt. Rahmad Abdillah, S.Farm., M.Si. sebagai tim dosen pengawas Praktikum Farmakoterapi Penyakit Saluran Cerna, Saluran Nafas, dan Kondisi Khusus yang telah terlibat dalam perancangan dan pelaksanaan praktikum ini.

\section{DAFTAR PUSTAKA}

1. Lang W. The role of academic pharmacy to influence safety through science and education. Am J Pharm Educ. 2011;75(4):78.
2. Pearson ML, Hubball HT. Curricular Integration in Pharmacy Education. Am J Pharm Educ [Internet]. 2012;76(10):204. Available from: http://10.0.22.56/ajpe7610204

3. Toklu HZ, Hussain A. The changing face of pharmacy practice and the need for a new model of pharmacy education. J Young Pharm [Internet]. 2013;5(2):38-40. Available from: http://www.sciencedirect.com/science/article/ pii/S0975148313000058

4. Chanakit T, Low BY, Wongpoowarak P, Moolasarn S, Anderson C. A Survey of Pharmacy Education in Thailand. Am J Pharm Educ [Internet]. 2014 Nov 15;78(9):161. Available from: http://www.ajpe.org/content/78/9/161. abstract

5. Skelley JW, Firth JM, Kendrach MG. Picking teams: Student workgroup assignment methods in U.S. schools of pharmacy. Curr Pharm Teach Learn [Internet]. 2015;7(6):745-52. Available from: http://www.sciencedirect.com/science/ article/pii/S1877129715000945

6. Chamorro-Premuzic T, Furnham A, Lewis M. Personality and approaches to learning predict preference for different teaching methods. Learn Individ Differ [Internet]. 2007;17(3):241-50. Available from: http://www.sciencedirect.com/ science/article/pii/S1041608006000343

7. Menges RJ, Svinicki MD. College Teaching: From Theory to Practice [Internet]. John Wiley \& Sons; 1991. (New directions for teaching and learning). Available from: https://books.google. co.id/books?id=_h6dAAAAMAAJ

8. Persky AM, Henry T, Campbell A. An exploratory analysis of personality, attitudes, and study skills on the learning curve within a team-based learning environment. Am J Pharm Educ [Internet]. 2015 Mar 25;79(2):20. Available from: https://www.ncbi.nlm.nih.gov/ pubmed/25861101

9. Veluchamy R, Bharadwaj M., Vignesh S, Sharma G. Personal and Professional Attitudes of Architecture Students. IJCTA [Internet]. 2016;9(37):471-8. Available from: https:// www.researchgate.net/profile/Ramar_Hr2/ 
publication/323105814_Personal_and_ Professional_Attitudes_of_Generation_Z_ Students_Students'_Talent_Management/ links/5a7f38bfof7e9be137c72f2b/Personaland-Professional-Attitudes-of-Generation-ZStudents-Stude

10. Long A, Lock B. Understanding Medical Education. 2nd ed. Swanwick T, editor. Vol. 1, Lectures and large groups. Wiley Blackwell; 2014. 522 p.

11. Nusair MB, Guirguis LM. How pharmacists check the appropriateness of drug therapy? Observations in community pharmacy. Res Social Adm Pharm [Internet]. 2016/03/21. 2017;13(2):349-57. Available from: https:// www.ncbi.nlm.nih.gov/pubmed/27102265

12. Vyas D, Ottis EJ, Caligiuri FJ. Teaching clinical reasoning and problem-solving skills using human patient simulation. Am J Pharm Educ [Internet]. 2011 Nov 10;75(9):189. Available from: https://www.ncbi.nlm.nih.gov/ pubmed/22171117

13. Wright DFB, Anakin MG, Duffull SB. Clinical decision-making: An essential skill for 21st century pharmacy practice. Res Soc Adm Pharm. 2019;15(5):600-6.

14. Ghaibi S, Ipema H, Gabay M. ASHP guidelines on the pharmacist's role in providing drug information. Am J Heal Pharm. 2015;72(7): 573-7.

15. American Pharmacists Association. Pharmacists' Impact on Patient Safety. 2016; Available from: https://www.pharmacist.com/sites/default/ files/PharmacistsImpactonPatientSafety_Web. pdf

16. Sanii Y, Torkamandi H, Gholami K, Hadavand N, Javadi M. Role of pharmacist counseling in pharmacotherapy quality improvement. J Res Pharm Pract [Internet]. 2016;5(2):132-7. Available from: https://www.ncbi.nlm.nih.gov/ pubmed/27162808
17. Doucette WR, McDonough RP, Klepser D, McCarthy R. Comprehensive medication therapy management: identifying and resolving drug-related issues in a community pharmacy. Clin Ther [Internet]. 2005 Jul;27(7):1104-11. Available from: https://www.ncbi.nlm.nih.gov/ pubmed/16154490

18. Katajavuori N, Salminen O, Vuorensola K, Huhtala H, Vuorela P, Hirvonen J. CompetenceBased Pharmacy Education in the University of Helsinki. Pharm (Basel, Switzerland) [Internet]. 2017 Jun 1;5(2):29. Available from: https:// www.ncbi.nlm.nih.gov/pubmed/28970441

19. Vera N, Young L, Sweet L. Assessing the Alignment of Pharmacotherapeutics Course Outcomes With Topic Outcomes. Am J Pharm Educ [Internet]. 2019 Apr;83(3):6545. Available from: https://www.ncbi.nlm.nih.gov/ pubmed/31065152

20. Moravec M, Williams A, Aguilar-Roca N, O’Dowd DK. Learn before lecture: A strategy that improves learning outcomes in a large introductory biology class. CBE Life Sci Educ [Internet]. 2010;9(4):473-81. Available from: https://pubmed.ncbi.nlm.nih.gov/21123694

21. Coulter CJ, Smith S. The impact of preclass reading assignments on class performance. Curr Pharm Teach Learn [Internet]. 2012;4(2):109_ 12. Available from: http://www.sciencedirect. com/science/article/pii/S1877129712000093

22. Lieu R, Wong A, Asefirad A, Shaffer JF. Improving Exam Performance in Introductory Biology through the Use of Preclass Reading Guides. CBE Life Sci Educ. 2017;16(3). 